\title{
A Study on unit commitment taking uncertainties in forecast of renewable energy outputs into consideration
}

\author{
Eiji Nishiura , and Ryuji Matsuhashi \\ The University of Tokyo, 7-3-1 Hongo Bunkyo-ku, Tokyo 113-8654, Japan
}

\begin{abstract}
The rapid increase of photovoltaics causes serious problems in Kyushu area. Renewable energy output has fluctuation and it becomes more difficult to ensure reserves, so a risk of power suppression has been considered now. The forecast for PV power output is developed, by using multiple regression and lasso regression analysis. Uncertainties of renewable energy must be taken into consideration when modeling the power system. In this study, uncertainties are taken into consideration as stochastic unit commitment. In addition, it is shown that rescheduling of UC can adjust generation units schedule when forecast error is large.
\end{abstract}

Keywords: Photovoltaics, regression analysis, uncertainty of renewable energy, unit commitment

\section{Introduction}

Now, a lot of renewable energy resources are introduced in order to reduce $\mathrm{CO} 2$ emission. However, it causes some problems at the same time.

It is difficult to store electric power, so the balance between demand and supply is important. The outputs of renewable energy resources, especially photovoltaics and wind power generations, depend on natural conditions. For example, solar irradiance, the amount of clouds and the speed of wind have much influence on the fluctuation of renewable energy outputs. Introducing a large amount of renewable energy threatens the stability of the power system.

From the report of Kyushu electric power company [1], photovoltaic is rapidly increasing. As a result, the output of PV reaches $66 \%$ of all electricity demand in the daytime. The fluctuation of PV output is absorbed by thermal power plants and pumped storage system. If more amount of PV is introduced, the suppression of PV output cannot be avoided [2].

\section{Forecast Model of PV Output}

Forecasting method is important to operate the power system with safety and efficiency. It is classified into several types: simulation of weather based on the meteorological model, analysis of satellite images, and statistical analysis [3][4]. This research adopts the statistical method.

\subsection{Multiple regression analysis}

In the forecasting method used in [5], multiple regression analysis is adopted. It calculates the relative equation of PV output and weather conditions from the actual output and forecasted weather conditions in the past. This method is used in this research and equation is set as equation (1). PV output, $\mathrm{X}(\mathrm{t})$, is explained variable. Solar irradiance X0 (t), the amount of clouds (TCDC) and rain dummy (DA) are explanatory variables.

\footnotetext{
* Manuscript received August 23, 2018; revised May 6, 2019.

Corresponding author. E-mail address: nishiura@enesys.t.u-tokyo.ac.jp

doi: $10.12720 /$ sgce.8.4.392-396
} 


$$
X(t)=X_{-} 0(t) *\left(a \_0+a \_1 * T C D C+a \_2 * D A+a_{-} 3 * D A * T C D C+\varepsilon\right)
$$

Input data is GPV/GSM data provided by the Japan Meteorological Business Support Center [6]. This data is provided 4 times a day $(3,9,15,21$ o'clock) and includes temperature, the amount of clouds and precipitation which forecasts from 1 hour to 84 hours ahead. The data for 1 year is used, and 2/3 of it is used as training data of regression and $1 / 3$ is used as test data. PV power output is estimated based on actual solar irradiance, precipitation and air mass using the method in [7][8][9]. In this regression model, 24 grid points observing weather in Kyushu area are considered and PV output is forecasted from 1 hour to 39 hours ahead.

\subsection{Lasso regression analysis}

Although the regression equation is calculated now, the number of explanatory variables is 73 . Some of them are not statistically significant because p-values are large. When explanatory variables are too many, the model fits training data and it can cause overfitting. Therefore, it is important to extract significant variables. This research uses lasso regression for extracting variables. The norm of the regression coefficient is added to the minimized function of least-square method as equation (2). By using this method, coefficients of some variables become zero. If the coefficient is zero, the variable has no influence and is excluded from explanatory variables.

$$
\operatorname{Min} \Sigma\left|Y-\Sigma\left(a_{-} i * X_{-} i\right)\right|+\lambda \Sigma\left|a_{-} i\right|
$$

\subsection{Result of PV forecast}

Fig. 1 shows the result of the forecast. Forecasted output and test data are compared, and then RMSE (Root Mean Square Error) is calculated. RMSE of lasso regression is relatively smaller than that of multiple regression and RMSE is larger when forecast time is large. Average values of RMSE are 9.1\% for multiple regression and $8.1 \%$ for lasso regression. Previous researches from METI's report say that RMSE is about $8.2 \%-12.2 \%$ [10]. This research's result is not so different from that referred values.

\section{Unit Commitment with Uncertainties}

In this chapter, an operational solution is researched. The power company has to make an operational plan of supplying electricity because some kinds of power plants cannot start or stop rapidly. Based on forecast of next day's demand, power system operators decide an optimal combination of power generation units which have various costs or characters. The objective function is operational cost and fuel cost, and constraints include reserve capacity. This optimization problem is called Unit Commitment (UC). It is an important thing that UC is based on forecast data on demand or renewable power. Forecast in the day before is not perfect, so it includes forecast error. In the case that forecast error is larger than considered, it can cause shortage or surplus of electricity.

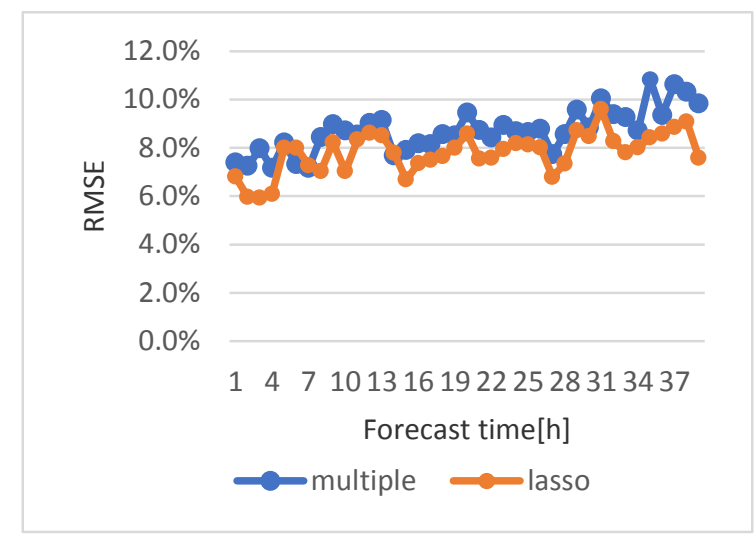

Fig. 1. RMSE of multiple regression and lasso regression 


\subsection{Stochastic unit commitment}

There is a type of unit commitment in which uncertainties are added to calculate function [11]. Stochastic unit commitment is now adopted. This is the method to apply stochastic analysis to UC. Some scenarios with certain probability distribution are assumed and the expectation value of cost multiplied by each probability is minimized. Equation (3) shows the objective function of the optimization problem.

$$
\operatorname{Min}\left[\boldsymbol{c}^{\wedge} T * \boldsymbol{u}+\Sigma\left\{\operatorname{Prob}_{-} s * F(\boldsymbol{u}, s)\right\}\right]
$$

Vector ' $\mathbf{u}$ ' is decision vector of unit commitment and is a binary variable. Vector ' $\mathbf{c}$ ' is start-up cost of the unit, and the first item means start-up cost of started units. The second item is calculated by summarizing fuel cost function ' $F$ ' multiplied with probability for each scenario. Constraints of optimization are balancing demand and supply power, upper/lower limit of the output of generation units, upper/lower limit of ramping rate and reserve capacity.

The constraint of reserve capacity is important. The definition of the amount of capacity is explained. Forecast error is approximated by Laplace distribution in [13]. The equation (4) is probability based on RMSE and error from the average value. The error from forecasted value is represented as ' $\mathrm{dx}$ ' and RMSE is sigma. From this distribution function, scenarios are divided into 6 groups as shown in Table 1.

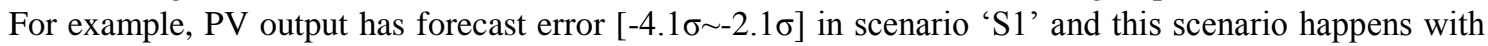
$2.1 \%$ probability.

$$
P(d x)=\exp (-\sqrt{2}|d x| / \sigma) / \sqrt{2} \sigma
$$

Table 1. Error band and probability for each scenario

\begin{tabular}{lll}
\hline Scenarios & Error band & Probability \\
\hline S1 & $-4.1 \sigma \sim-2.1 \sigma$ & $2.1 \%$ \\
S2 & $-2.1 \sigma \sim-0.8 \sigma$ & $13.6 \%$ \\
S3 & $-0.8 \sigma \sim 0$ & $34.1 \%$ \\
S4 & $0 \sim 0.8 \sigma$ & $34.1 \%$ \\
S5 & $0.8 \sigma \sim 2.1 \sigma$ & $13.6 \%$ \\
S6 & $2.1 \sigma \sim 4.1 \sigma$ & $2.1 \%$ \\
\hline
\end{tabular}

\subsection{Setting of parameters}

Table 2 shows the parameters of generation units. These settings are influenced by the real situation in Kyushu area [14]. Fig. 2 shows load factor of thermal power generation with partial load. Load factor curve is investigated in [15] and is approximated by a step function in order not to be non- linear. Hydro, biomass and geothermal power are assumed that they have a constant output by referring to the simulation by Kyushu electric power company [2].

\begin{tabular}{|c|c|c|c|c|}
\hline & $\begin{array}{l}\text { The number of units } \\
\text { (total capacity) }\end{array}$ & Available load factor & $\begin{array}{l}\text { Fuel cost } \\
\text { [yen } / \mathrm{kWh} \text { ] }\end{array}$ & $\begin{array}{l}\text { Start-up cost } \\
\text { [yen/MW] }\end{array}$ \\
\hline Coal & 4 (2.46GW) & $35-100 \%$ & 5.5 & - \\
\hline LNG & $17(4.55 \mathrm{GW})$ & $\begin{array}{l}\text { Combined Cycle : } 40-100 \% \\
\text { Conventional : } 25-100 \%\end{array}$ & 10.8 & 2000 \\
\hline Oil & $4(2.00 \mathrm{GW})$ & $25-100 \%$ & 21.7 & 2000 \\
\hline Nuclear & $5(4.70 \mathrm{GW})$ & $100 \%$ & 1.5 & - \\
\hline Pump & $1(2.30 \mathrm{GW})$ & $0-100 \%$ & - & - \\
\hline
\end{tabular}

Table 2. Parameters of generation units

\subsection{Result of unit commitment}

Fig. 3(a) shows the result of unit commitment calculated from optimization. When PV power output is small in the morning and evening, nuclear, coal and LNG thermal power supply electricity. In the daytime, PV output is large, and then coal and LNG power plants work at partial load in order to provide reserve 
power. Pumped storage power plant absorbs surplus PV power in the daytime and generates electricity at other times.

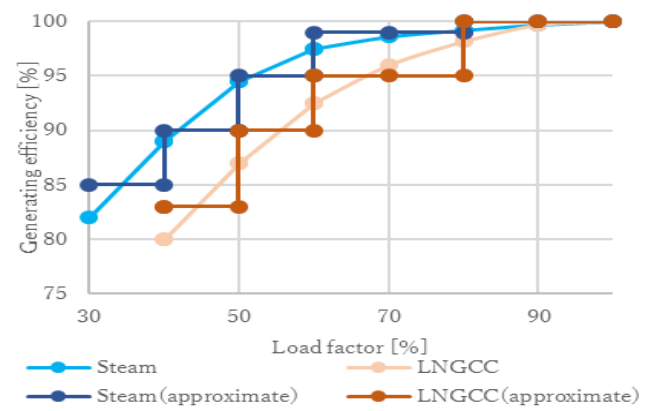

Fig. 2. Load factor of thermal power generation units

\section{Rescheduling of Unit Commitment}

Unit commitment is based on forecast data created at 9 a.m. of the previous day. However, forecast error is small when forecast time is short as shown in fig. 1. Based on this information, unit commitment of the day before is adjusted intraday. The intraday forecast is more accurate, so less amount of reserve is needed. Specifically, the forecast of PV output is performed again at $3 \mathrm{a}$.m. of the day, the time when GPV data is provided. By using this forecast data, the operation plans after 6 o'clock can be rescheduled. Oil, LNG, LNG combined cycle plants can start or stop in a relatively short time and can adjust operation. On the other hand, coal thermal power and nuclear power plants cannot operate at daily start and stop, so rescheduling of them is not considered in this research.

Fig. 3(b) shows the result of the rescheduled unit commitment. This is the case that the output of intraday forecast is larger than that of the previous forecast. In unit commitment planed in the day before, LNG power plants can operate at partial load in the daytime, but PV output becomes larger and then LNG plants stop. Moreover, coal power plants reduce their output as around minimum output. In the evening, LNG combined cycle plants are started up. This is because multi-shaft combined cycle has a lot of generators with small capacity in parallel, and some combined cycle plants are started up and each can operate at around rated output efficiently.

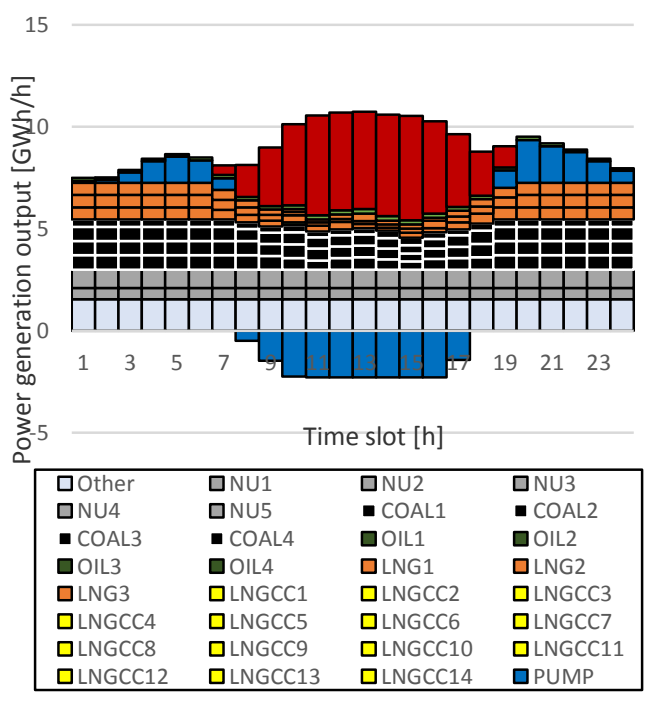

(a)

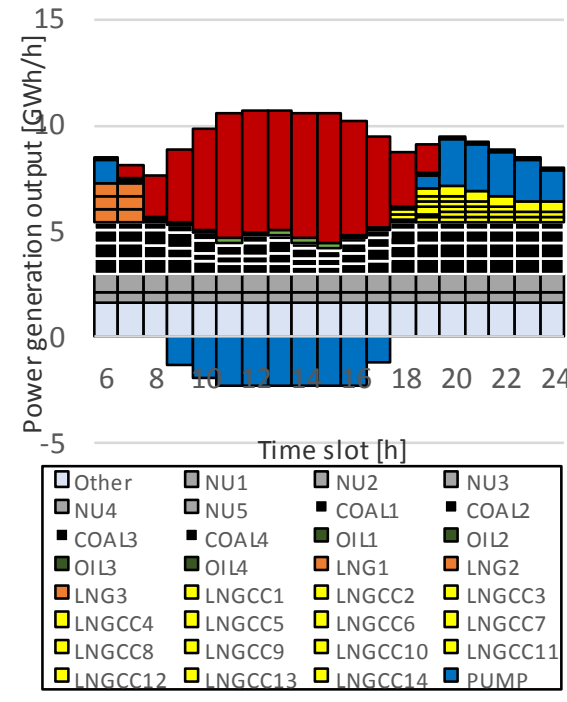

(b)

Fig. 3. Unit commitment (a) planned on the previous day, and (b) rescheduled on the day 


\section{Conclusion and Future Works}

Renewable energy is rapidly increasing and it causes the problem of power system stability. This research focuses on the strategy to deal with uncertainties of renewable energy outputs. Multiple regression and lasso regression models are proposed and RMSE is analyzed. In addition, seasonal effects and detailed analysis considering weather condition should be studied more, and the accuracy of the forecast can be improved.

Unit commitment model taking uncertainties into consideration is proposed as the operational strategy. Uncertainties are assumed as scenarios and the economically optimal plan is made. Moreover, unit commitment is rescheduled based on the difference between the previous day and intraday forecast accuracy. In the case that PV output becomes larger than forecasted, the optimal operation changes in the daytime and evening. In this research, PV is focused on and forecast error of demand and wind power is not considered. All factors should be included in analysis and model influenced by real situation should be built by annual simulation.

\section{References}

[1] Kyushu electric power company (2016). Available: http://www.kyuden.co.jp/var/rev0/0055/4420/2ntja6f6cpd.pdf

[2] Ministry of Economy, Trade and Industry (2017). Available: http://www.meti.go.jp/committee/sougouesougo/shoene_shinene/shin_ene/keitou_ww/pdf/012_01_08.pdf

[3] Ishibashi N, lizuka T, Katsuno T. Photovoltaic power generation forecasting technology for supporting energy management systems. Fuji Electric Review. 2013; 86(3).

[4] Nagoya H, Saiji K, Aoki I, Tanikawa R, Komami S, Ogimoto K, Iwafune Y. A study on irradiance forecast accuracy on NumZerous points correspond to highly penetrated PVs using numerical weather prediction data by Japan meteorological agency. IEEJ Transactions on Power and Energy, 2013; 133(6):531-540

[5] Takahashi M, Matsuhashi R. Area-wide total wind and photovoltaic power forecasting using multiple regression technique and analysis of forecast error characteristics. Journal of Japan Society of Energy and Resources. 2017; 38(5):1-8.

[6] Japan Meteorological Business Support Center. Available: http://www.jmbsc.or.jp/jp/online/f-online0.html\#file311

[7] Japan Solar Energy Society, New Solar Energy Utilization Handbook, 2000.

[8] JIS C8907-2005, Estimation method for generating electric energy by PV power system.

[9] Yamagishi Y, Fujii Y. Accuracy verification of arbitrary point insolation estimation using the automated meteorological data acquisition system data. IEEJ Transactions on Power and Energy. 2012; 132(1):65-70.

[10] Ministry of Economy, Trade and Industry (2013).

Available: http://www.meti.go.jp/policy/tech_evaluation/c00/C0000000H25/141219_denryoku2/denryoku2_siryou2_4_5.pdf

[11] Zheng QP, Wang J, and Liu AL. Stochastic Optimization for Unit Commitment - A Review. IEEE Transactions on Power Systems. 2015; 30(4): 1913-1924.

[12] Bertsimas D, Litvinov E, Andy SX, Zhao J, Zheng T. Adaptive robust optimization for the security constrained unit commitment problem. IEEE Transactions on Power Systems. 2013; 28(1).

[13] Takahashi M, Matsuhashi R. A cost reduction analysis of introduction of battery energy storage and controllable heat pump water heaters by operation planning model of power generation system considering the uncertainty in renewable power generation. IEEJ Transactions on Power and Energy. 2017; 137(12): 756-765.

[14] Kyushu electric power company (2015). Power generation equipment. Available: http://www.kyuden.co.jp/effort_outline.html

[15] Yamamoto H, Bando S, Sugiyama M. Development of a power Generation Mix Model Considering Multi Modes of Operation of Thermal Power Fleets and Supply-Demand Adjustability. CRIEPI report (2013). 